\title{
Maestría en Pedagogía de la lengua materna
}

María Elvira Rodríguez Luna

plengua@udistrital.edu.co

Coordinadora

$\mathrm{C}$ on la aprobación del Consejo Superior Universitario (Resolución $013 \mathrm{del}$ 27 de mayo de 2008) y el otorgamiento por siete años del Registro Calificado por parte del Ministerio de Educación Nacional (SNIES 54328), la Facultad de Ciencias y Educación de la Universidad Distrital inició -el pasado mes de agosto de 2009la primera cohorte de la Maestría en Pedagogía de la lengua materna. Este programa está dirigido principalmente a docentes en ejercicio en los distintos niveles de la escolaridad, profesionales con funciones pedagógicas e investigadores en el campo de la lectura y la escritura que acrediten título de pregrado en Ciencias del lenguaje o Ciencias Humanas y Sociales, Pedagogía, Educación o áreas afines.

Las actividades curriculares tienen una duración aproximada de cuatros semestres a lo largo de los cuales se cursan 48 créditos a través de seminarios, talleres, prácticas de profundización y acciones complementarias. Tales espacios académicos permitirán contar con una sólida fundamentación sobre el len- guaje, la lengua y el discurso; la investigación sobre las actividades del lenguaje en el contexto educativo y las estrategias pedagógicas y didácticas necesarias para el óptimo desempeño de un docente / investigador..

Mediante un currículo flexible, dinámico y pertinente, los egresados estarán en condiciones de responder a los lineamientos propuestos por los organismos nacionales e internacionales respecto a la educación $y$, particularmente, a la pedagogía de la lengua materna en cuanto cualificarán sus competencias lingüístico-discursivas, pedagógico-didácticas, investigativas, comunicativas y socioafectivas.

La articulación de estas competencias favorecerá su autonomía, responsabilidad y proyección con base en el trabajo cooperativo y la capacidad para organizar y desarrollar acciones en equipo como expresiones de los procesos de autogestión. A su vez, éstas aportarán al mejoramiento de los procesos de la oralidad (habla y escucha), de la escritura (lectura y escritura) y de otras competencias 
necesarias para la construcción de conocimientos y saberes. De este modo responde a las demandas de los egresados de esta Maestría y áreas afines, y otros profesionales de la educación en la Ciudad Región, articulándose a los planes de desarrollo sectorial y local, dada la transversalidad de los procesos lingüísticos en la investigación sobre problemas ligados al fortalecimiento de la competencia comunicativa de los ciudadanos.

Como consecuencia del fortalecimiento y la conformación de nuevos núcleos de investigación en las diversas instituciones donde se desempeñan profesionalmente los estudiantes, la Maestría apunta a la consolidación de comunidad académica y el trabajo en redes. Tales propósitos guían el accionar del grupo Lenguaje, Cultura e Identidad (Clasificado en el Sistema de Investigación Científica y Tecnológica de Colciencias) desde las siguientes líneas la escritura.

- Actividades discursivas de la oralidad y

- Concepciones de los docentes y prácticas pedagógicas.

- Pedagogía de proyectos y aprendizajes significativos.
- Evaluación interna y externa de los aprendizajes en lengua materna.

Como complemento a la labor formadora e investigativa, la Maestría ha suscrito convenios con prestigiosas instituciones, entre las cuales se destacan la Universidad Católica de Temuco, la Universidad Paris 3 (Sorbonne Nouve1le), la Universidad Paris 5 (René Descartes), la Universidad Iberoamericana de México y la Universidad de Granada, y cuenta con el apoyo permanente del Doctorado Interinstitucional en Educación (Universidad del Valle, Universidad Distrital, Universidad Pedagógica Nacional) y el Grupo de Investigación en Evaluación de la Universidad Nacional, entre otros. Con un equipo docente de las más altas condiciones académicas, experimentado en procesos de formación e investigación, y respaldado por la trayectoria de la Universidad Distrital, la Maestría en Pedagogía de la lengua materna, sin duda alguna, se constituye en una opción de bajo costo y excelente calidad para quienes deseen continuar su cualificación profesional e investigativa en este nivel de posgrado. 